\title{
A Bidirectional Contactless Power Transfer System Based on Quantum Modulation
}

\author{
Jianyu Lan* and Houjun Tang \\ Department of Electrical Engineering, \\ School of Electronic Information and Electrical Engineering, \\ Shanghai Jiao Tong University \\ Dong chuan RD., NO. 800, 200240, Min hang, Shanghai, China \\ *Jianyu_lan@163.com
}

\begin{abstract}
Contactless power transfer is an emerging technology. It is widely used in industrial and consumer electronic products. In this paper, a bidirectional contactless power transfer system for wireless vehicle charger is presented based on quantum modulation method. By applying this novel amplitude modulation method, switching losses and electromagnetic noise are greatly reduced and the whole system efficiency increased as well Firstly, the operational principle of the contactless power transfer system is reviewe C. The frequency analysis of the contactless power transfer system based on series resonan converter is deduced in detail. Besides, the voltage gain and phase feature of resonant ank are shown. Then, the quantum method for bidirectional power flow is explained in detail. The controller framework based on a simple analogous circuit is analysed as welt. In additional, a simulation of the bidirectional contactless power transfer systembased on quantum modulation by computer is presented to demonstrate the effectiveness of this method. Then, the conclusion of contactless power transfer system of bidinectional power flow is given at the end.
\end{abstract}

Keywords: contactless power transfer, vehicle charger, quantum modulation, voltage gain

\section{Introduction}

Compared with traditional power transfer method with plugs and sockets, electronic products with contactless power transfer (CPT) technology have considerable advantages. This technology enableselectronic products to work freely and safely in hostile environments such as under water, under mine and in dusty situations. Therefore, the CPT technology is employed in numerous applications ranging from low power to high power electronic products which can be found in biomedical implants, vehicle chargers, universal platform chargers or consumer electronics and so on [1-6]. In particular, the CPT systems are preferable for vehicle chargers because of its convenient and safe operation in rainy day. Works focused on the CPT systems for vehicle battery chargers are presented in [7] to [14]. In [7], design considerations for the wireless electric vehicle battery charger are presented, in which a variable frequency controller is used. In addition, the optimal design methods for a maximum efficiency of a CPT system to the vehicle battery charger are shown in [8] to [10]. Furthermore, multi-phase pickup for a large lateral tolerance contactless power transfer system is discussed in [11]. However, the electric vehicles and vehicle to grid systems need a bidirectional power flow system to feed back the battery power to grid for saving energy of electric vehicles. Thus, CPT systems with the function of bidirectional power flow are attractive for these applications [12-18]. U. K. proposed a bidirectional inductive power 
interface for vehicles inV2G systems [12-14]. Moreover, a dynamic multivariable state-space model for bidirectional inductive power transfer systems is presented [15]; D. J. focused on the synchronization technique for bidirectional IPT systems [16]. On the other hand, other works pay attention to controller design of bidirectional CPT systems. A varying frequency controller for bidirectional inductive power transfer systems is explained in [17]. The optimal PID controller for bidirectional inductive power transfer system using multi-objective genetic algorithm is shown in [18].

With high efficiency for the whole load range of resonant converters, the quantum modulation is proposed in [19]. The novel modulation method introduced a discrete energy control to CPT systems. With quantum modulation, the switches turn on and off at the zeroacross point of resonant tank current, which ensuring soft switching at all of the load range. Thus, the efficiency increases greatly than varying frequency controller or phase-shift controller [19-25]. A quantum control for multiple users CPT system is proposed in [19] The current fluctuation analysis of a quantum CPT system is presented in [21], which is helpful for the design of CPT system based on quantum modulation. Furthermore, the sliding mode control for quantum CPT system is discussed in [21] to [26].

Unfortunately, above arts about bidirectional CPT system are mainly based on varying frequency and shift-phase modulation with low efficiency when the load is away from rated value. On the other hand, to ensure two-way power flow, a complex synchronous technology of the pulse should be exert to two inverters based on primary side and secondary side. In this paper, a bi-directional CPT system with the LC-T-LC resonant-converter based on quantum modulation is analyzed. Based on this modulation, the efficiency of CPT system for the whole load range can be improved greatly compared with tradi innal modulation methods.

The paper is organized as follows: ir section 2 the operating principle and the modelling of the proposed CPT system is discussed finst; after which the quantum modulation is explained in detail in section 3. In section 4 a smulation study is carried out to verify the analysis. Final conclusions are shown in section 5 .

\section{Operation Principle of Contactless Power Converter}

A bidirectional CPT system of a yehjcle battery charger is presented in this paper and the block diagram is hown in Figure 1. It consists of two identical full-bridge inverters and a LC-T-LC resonany converter.Bidirectional power flow can easily be controlled from primary side to secondary side by adjusting the logical principle of switches of the two inverters.

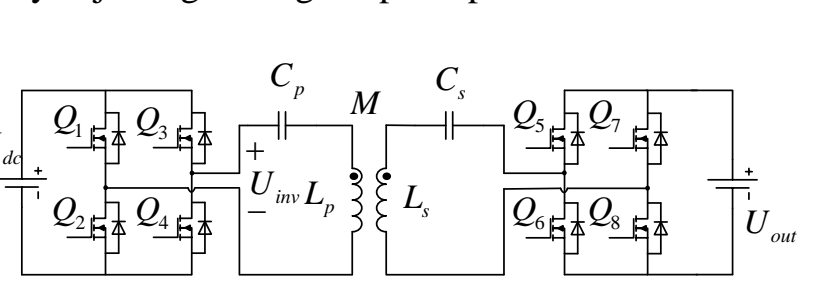

Figure 1. Topology of Bidirectional Contactless Power Transfer System

Figure 2 shows the T-type transformer model of the LC-T-LC resonant converter. The capacitor $C_{\mathrm{p}}$ and $C_{\mathrm{s}}$ are placed on the primary side and the secondary side, respectively, to compensate the large leak inductance. 


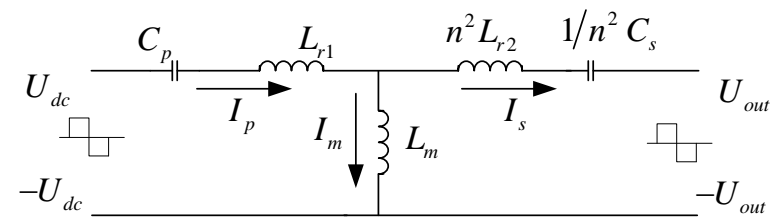

Figure 2. T-style Model of Contactless Power Transfer System

Observed from Figure 2, the impedance of the transformer is represented as (1) and (2):

$$
\begin{aligned}
& Z_{1}=\frac{1}{s C_{p}}+s L_{r 1}+s L_{m} / /\left(s L_{r 2}+\frac{1}{s C_{s}}+R_{L}\right) \\
& Z_{1}=\frac{1}{s C_{p}}+s L_{r 1}+\frac{s^{3} L_{r 2} L_{m} C_{s}+s^{2} L_{m} C_{s} R_{L}+s L_{m}}{s^{2} L_{r 2} C_{s}+s^{2} L_{m} C_{s}+s R_{L} C_{s}+1}
\end{aligned}
$$

And, the primary side coil current is expressed as

$$
I_{p}=\frac{U}{Z_{1}}
$$

The circuit equations are listed from (4) to (6) by using Kirchboff's current/voltage laws.

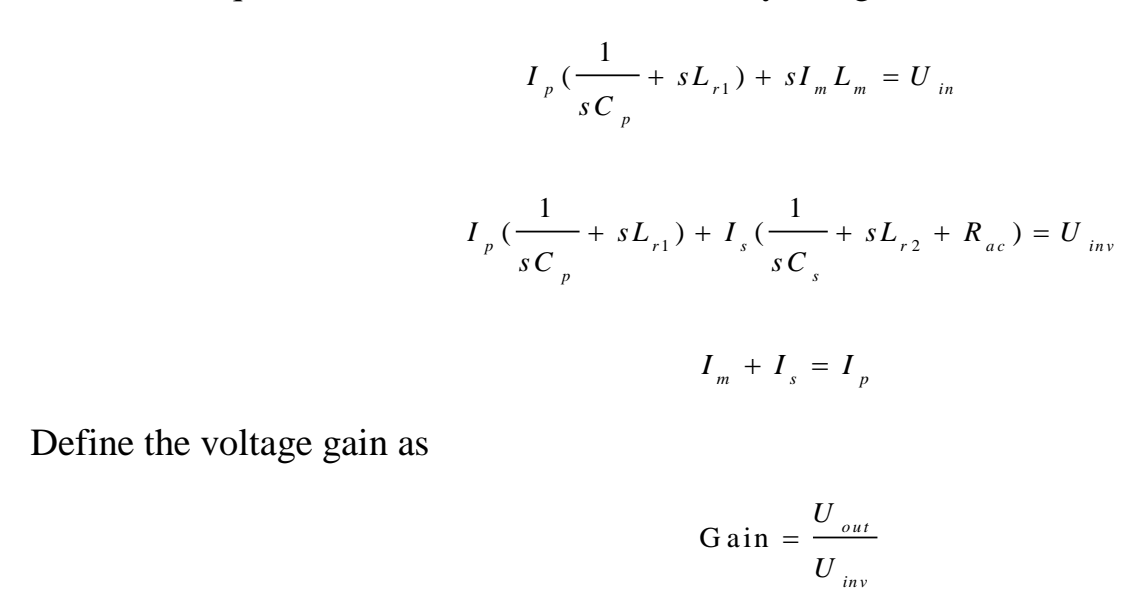

Then,

In which $R_{\mathrm{ac}}$ is the ac equivalent resistance,

$$
\frac{1}{\left(\frac{1}{s C_{p}}+s L_{r 1}+\frac{s^{3} L_{r 2} L_{m} C_{s}+s^{2} L_{m} C_{s} R_{a c}+s L_{m}}{s^{2} L_{r 2} C_{s}+s^{2} L_{m} C_{s}+s R_{L} C_{s}+1}\right)\left(\frac{1}{s C_{s}}+s L_{r 2}+s L_{m}+R_{a c}\right)}
$$

$$
R_{a c}=\frac{8}{\pi^{2}} R_{L}
$$

Let $s=\mathrm{j} \omega$, then the output voltage gain to $\omega$ is expressed,

$$
\text { Gain }=f(\omega)
$$


To analysis the gain feature of CPT system, differential equation of Gain to $\omega$ is shown

$$
\frac{d f(\omega)}{d \omega}=0
$$

Substituting (8), (9) into (10), the solver of equation (10) can be achieved, and the critical frequency is gotten,

$$
\begin{gathered}
\omega_{r 1}=\frac{1}{\sqrt{\left(L_{r 1}+2 L_{m}\right) C_{p}}} \\
\omega_{r 2}=\frac{1}{\sqrt{\left(L_{r 1}+L_{m}\right) C_{p}}} \\
\omega_{r 3}=\frac{1}{\sqrt{L_{r 1} C_{p}}}
\end{gathered}
$$

Figure 3 shows the analytical results in frequency domain. The Figure 3 (a) is the voltage gain about frequency, while (b) is the phase plot. To observe figue (a), there is a load independent point at frequency point $\omega_{\mathrm{r} 3}$. When the CPT system works at this frequency, the output voltage gain would not change at diverse loads. Look at the figure (b) which is the phase plot of the primary coil current in CPT system, when the phase is above $90^{\circ}$, the zero current switching is achieved; otherwise the zero yoltage switching is achieved. When, the system operate at the resonant frequency, the ZCS and ZVS are achieved simultaneously, which maintain a high efficiency ofCPT systems. To ensure the stability of CPT systems, a slight inductive load is preferred for the full-bridge, so here a little higher than the resonant frequency $\omega_{\mathrm{r} 3}$ is suggested.

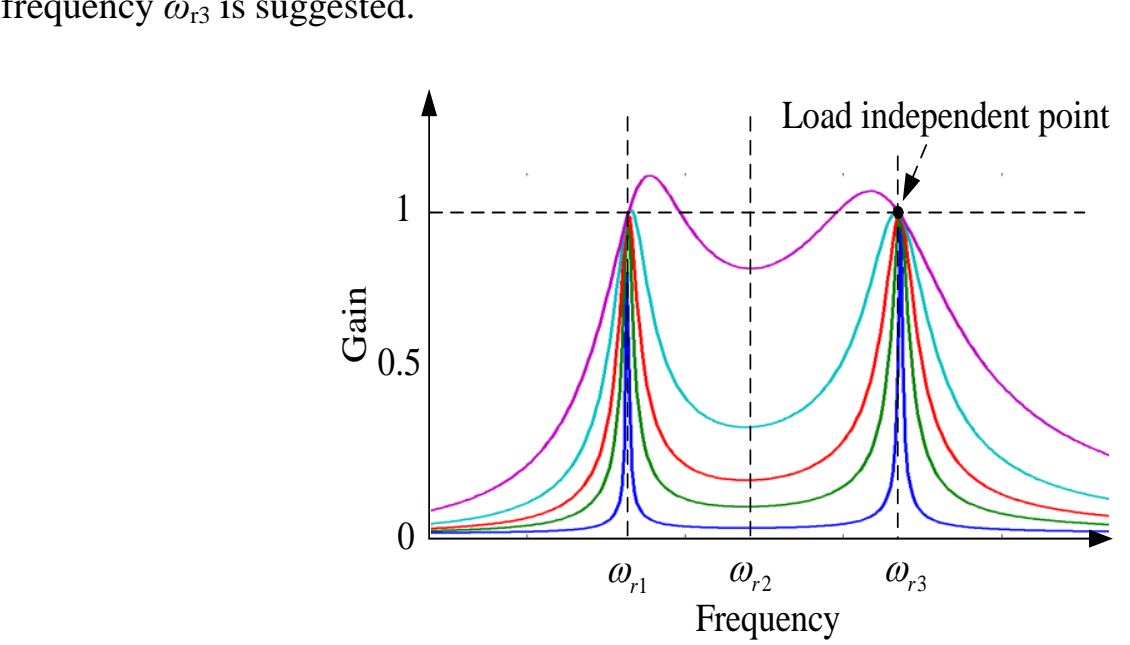

(a) Voltage Gain 


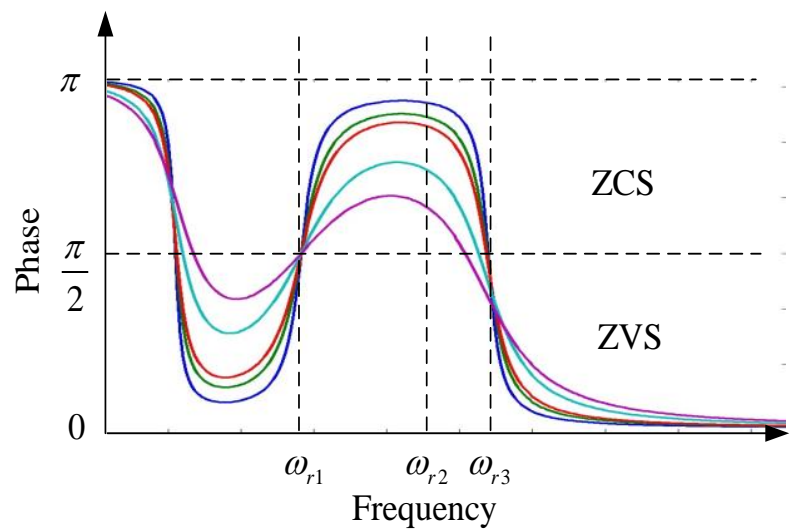

(b) Phase Plot

Figure 3. Frequency Features of LC-T-LC Resonant Converter

\section{Quantum Modulation}

\subsection{Operational Principle}

Quantum modulation is employed in this paper to control the bidirectional power flow of the CPT systems. The key scheme of quantum modulation is that the switching events happen at the resonant frequency which ensuring ZVS and ZCS in the whole operating range. Figure 4 shows typical waveforms of quantum nodulation in CPT systems.

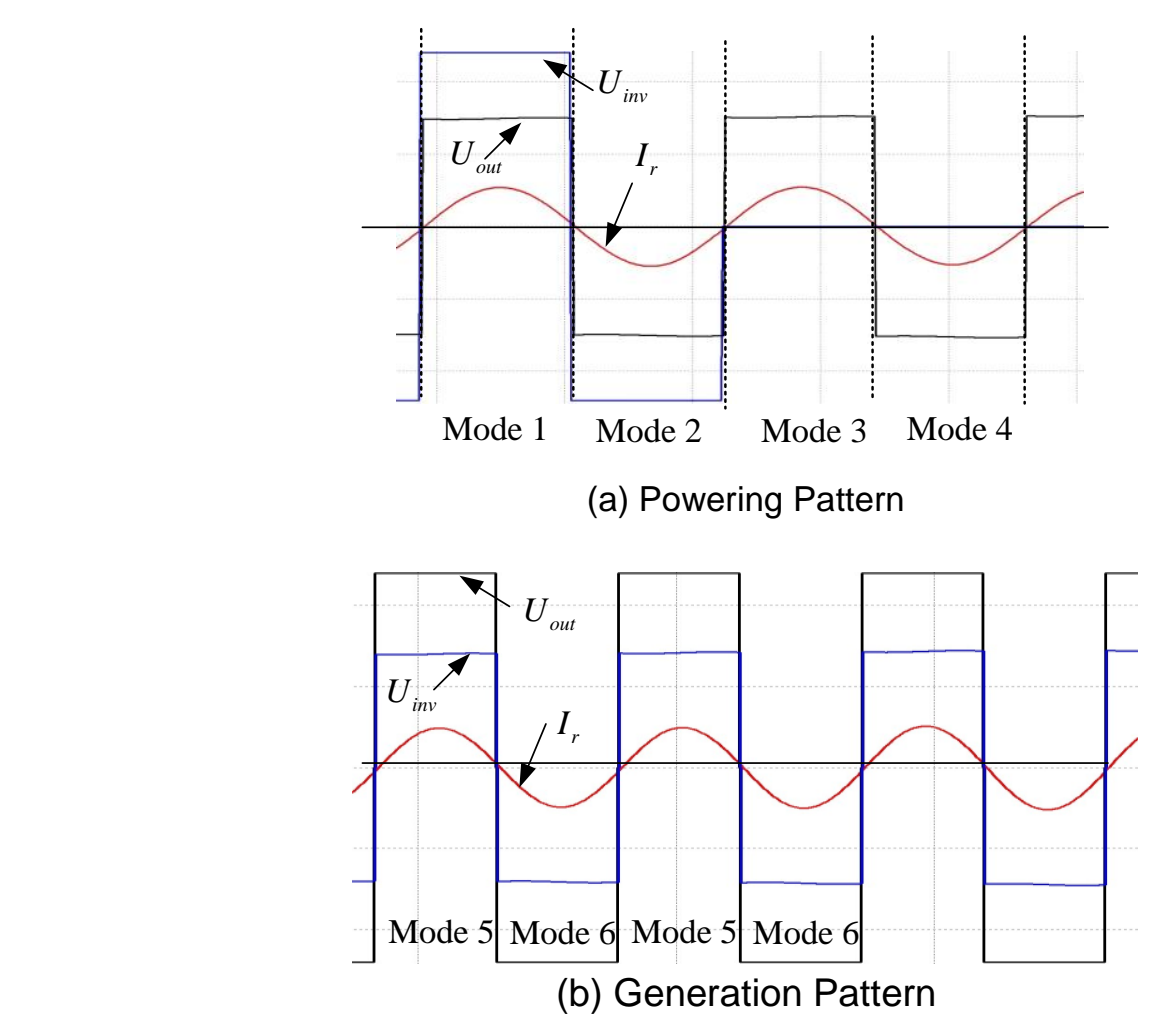

Figure 4. Mode Analysis of Quantum Modulation 
Figure 4 (a) shows the powering pattern of quantum modulation in which the power is transferred from primary side to secondary. The powering pattern consists of four modes, positive powering mode, negative powering, positive freely oscillation mode, negative freely oscillation mode. In mode 1 and mode 2 , the power is transferred from voltage source to battery, while in mode 3 and mode 4 , the power oscillates freely from resonant tank to load battery. In mode 3 and 4, the input voltage source is isolated from resonant tank, and the resonant tank feed energy to load battery.

Figure 4 (b) presents the generation pattern of quantum modulation which includes two modes, positive powering mode and negative powering mode. In this pattern, the output voltage is larger than input voltage, so the power is transferred from source to load.

Note to Figure 4, the input voltage and output voltage of resonant converter is square wave because their voltages are clamped by input voltage source and output battery respectively. On the other hand, the resonant current of primary side is a normal sinusoidal form This is because the switching frequency is exactly like the native resonant frequency which ensures high efficiency with soft switching.

\subsection{Switching Logics}

The switching logics are listed in Table 1 and Table 2 or the quantum modulation about the six modes. Table 1 is the switch status of primary inverter while Table 2 expresses the secondary switching status.

Table 1. Switching Principle of Primary Side Inverter
\begin{tabular}{|l|c|c|c|c|c|c|c|c|}
\hline Mode & $Q_{1}$ & $Q_{2}$ & $Q_{3}$ & $Q_{4}$ & $D_{1}$ & $\mathrm{D}_{2}$ & $\mathrm{D}_{3}$ & $\mathrm{D}_{4}$ \\
\hline 1 & Off & On & On & Off & Off & Off & Off & Off \\
\hline 2 & On & Off & Off & On & Off & Off & Off & Off \\
\hline 3 & On & Off & Off & Off & Off & Off & On & Off \\
\hline 4 & Off & Off & On & Off & On & Off & Off & Off \\
\hline 5 & Off & Off & Off & Off & Off & On & On & Off \\
\hline 6 & Off & Off & Off & Off & On & Off & Off & On \\
\hline
\end{tabular}

Table 2.Switching Principle of Secondary Side Inverter

\begin{tabular}{|l|c|c|c|c|c|c|c|c|c|}
\hline Mode & $Q_{5}$ & $Q_{6}$ & $Q_{7}$ & $Q_{8}$ & $\mathrm{D}_{5}$ & $\mathrm{D}_{6}$ & $\mathrm{D}_{7}$ & $\mathrm{D}_{8}$ \\
\hline 1 & Off & Off & Off & Off & On & Off & Off & On \\
\hline 2 & Off & Off & Off & Off & Off & On & On & Off \\
\hline 3 & Off & Off & Off & Off & Off & On & On & Off \\
\hline 4 & Off & Off & Off & Off & On & Off & Off & On \\
\hline 5 & On & Off & Off & On & Off & Off & Off & Off \\
\hline 6 & Off & On & On & Off & Off & Off & Off & Off \\
\hline
\end{tabular}

Figure 5 shows the detail of power flow under quantum modulation in resonant converter and the mode analysis is given as following. 


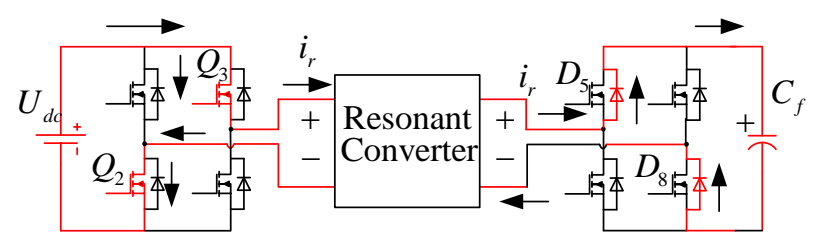

(a) mode 1

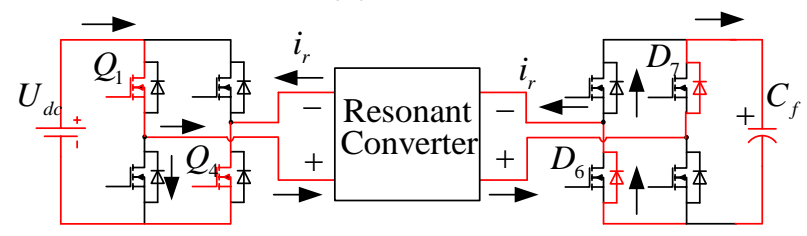

(b) mode 2

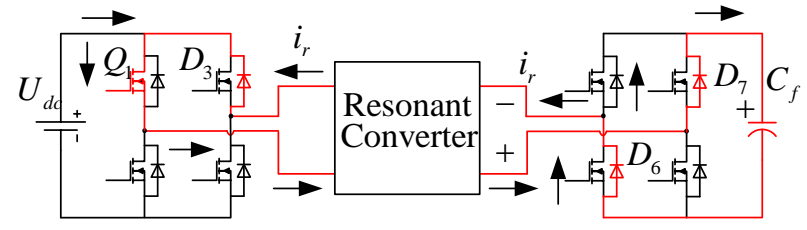

(c) mode

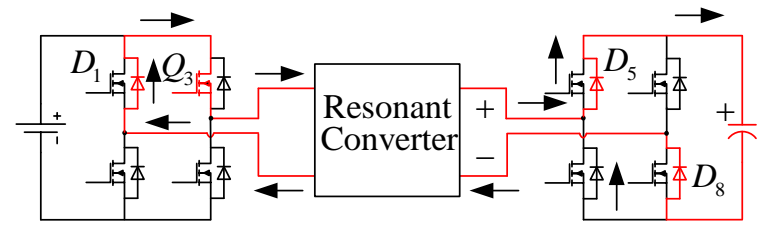

(d) mode 4
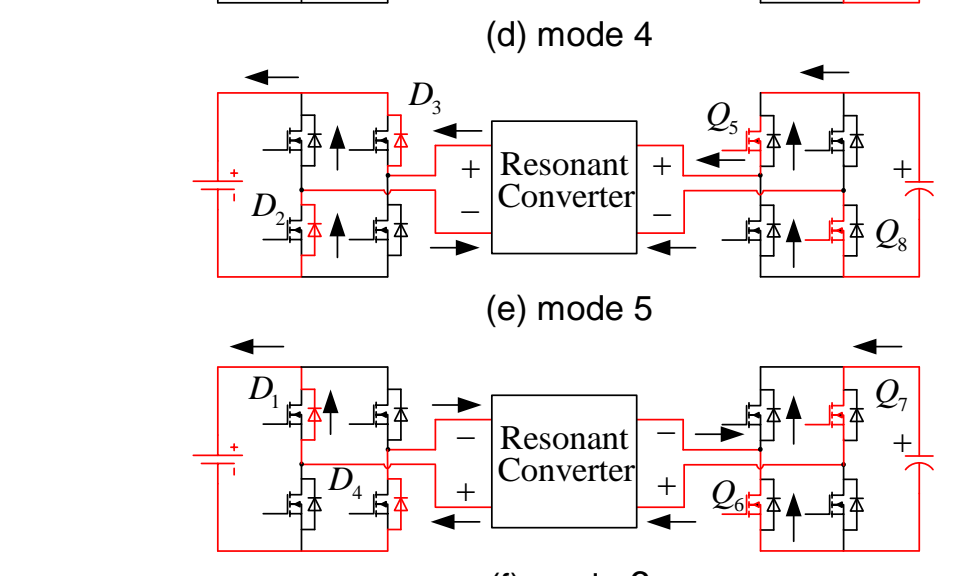

(f) mode 6

\subsection{Powering Mode (mode 1 and mode 2)}

Inpowering mode, the switches $Q_{1}, Q_{4}$ and $Q_{2}, Q_{3}$ turn on and turn off complementarily to delivery energy from source to load. In mode 1, the switch $Q_{3}$ and $Q_{2}$ turn on, the source voltage is feed on resonant converter. Because the source voltage is larger than load voltage, the freewheeling diodes $D_{5}$ and $D_{6}$ conduct in nature. In mode 2, the resonant current reverses. Then, the switches $Q_{3}$ and $Q_{2}$ turn on. Similarly, the freewheeling diodes on secondary inverter conduct in nature. 


\subsubsection{Freely Oscillation Mode (mode 3 and mode 4)}

In power oscillation mode, the source voltage isolates from resonant converter. In mode 3 , the switch $Q_{1}$ turns on, and other switches in primary inverter turn off. The power flows from resonant tank to load, and the switch $Q_{1}$ and freewheeling diodes $D_{3}$ provide energy path for resonant tank. In mode 4 , the resonant current reverses. Then, the switch $Q_{3}$ turns on. And the freewheeling diode $D_{1}$ naturally conducts.

\subsubsection{Generation Mode (mode 5 and mode 6$)$}

In generation stage, all switches in primary inverter turn off. $Q_{5}, Q_{8}$ and $Q_{6}, Q_{7}$ turn on alternatively to deal power from load to source. In Figure 6 (e), power flows from load to resonant tank when $Q_{5}$ and $Q_{8}$ turn on and off alternatively. At the same time, $D_{2}$ and $D_{3}$ turn on natively. Thus, power feedbacks to source voltage. When the resonant current reverses in (f), the switch $Q_{6}$ and $Q_{7}$ provide path from output voltage to source voltage Similarly, the freewheeling diodes $D_{1}$ and $D_{4}$ turn naturally at zero across point.

\subsection{Controller Framework}

The controller framework applied quantum modulation of bidirectional CPT systems is shown in Figure 6. At first, the output voltage is compared to reference voltage. Then, the error is compensated by a PI controller. The output value of PI controller is compared with zero through comparator $U_{1}$ to produce the mode signal $u(\mathrm{t})$. Afterwards, the mode signal $u(\mathrm{t})$ is synchronized by a D trigger $U_{2}$. At last, the quantum controller signal $u(k T)$ is added to logic gates $U_{3}$ to $U_{6}$ to produce gate pulse signal. Through the driver, the gate pulse signals are amplifier to drive switches from $Q_{1}$ to $Q_{8}$ of primary side inverters and secondary inverters.

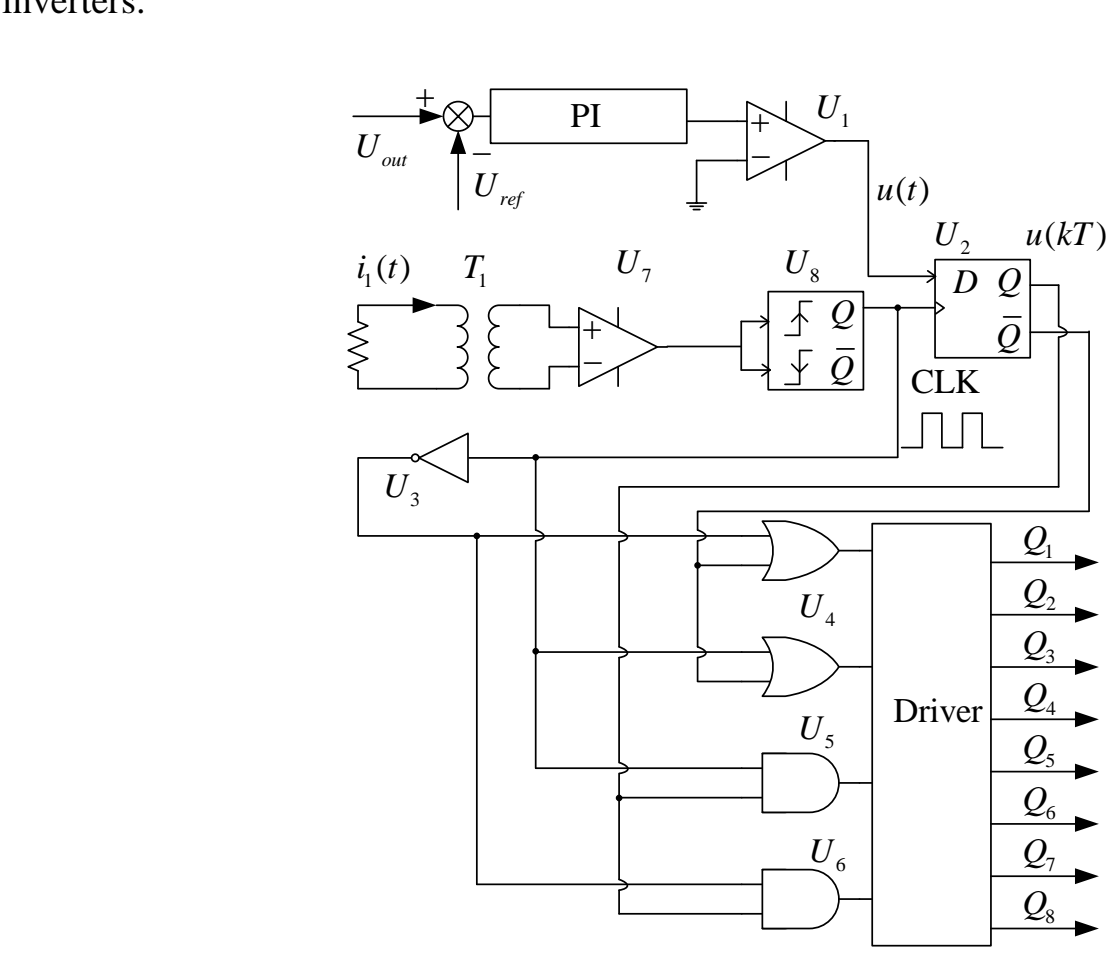

Figure 6. Controller Framework 


\section{Simulation Analysis}

To demonstrate the theoretical analysis, a simulation of the bidirectional CPT system in Figure 1 is constructed and tested. The nominal values of the power components and control parameters are listed in Table 3.

\section{Table 3. Circuit Parameters of the Bidirectional CPT System}

\begin{tabular}{|c|c|}
\hline Symbol & Value and part number \\
\hline$Q_{1}-Q_{8}$ & MOSFETs \\
\hline$D_{1}-D_{8}$ & Diodes \\
\hline$U_{\mathrm{dc}}$ & $24 \mathrm{~V}$ \\
\hline$C_{\mathrm{r} 1}$ & $4.7 n \mathrm{~F}$ \\
\hline$C_{\mathrm{r} 2}$ & $4.7 n \mathrm{~F}$ \\
\hline$L_{1}$ & $175 \mathrm{uF}$ \\
\hline$L_{\mathrm{m}}$ & $55 u \mathrm{~F}$ \\
\hline $\mathrm{C}_{\mathrm{f}}$ & $10 \mu \mathrm{F}$ \\
\hline$R_{\mathrm{L}}$ & $5 \Omega$ \\
\hline$U_{\mathrm{ref}}$ & $15 \mathrm{~V}$ \\
\hline$f_{\mathrm{r}}$ & $212 \mathrm{kHz}$ \\
\hline
\end{tabular}

The waveforms of proposed bidirectional CPT, system for the vehicle charger are shown from Figure 7 to Figure 8. Figure 7 shows the transient responses of the inverter voltage and the resonant current based on quantum modulation. Observed from Figure 7, the inverter voltage become zero when in the freely oscillation mode while in powering mode it is a pulse waveform.

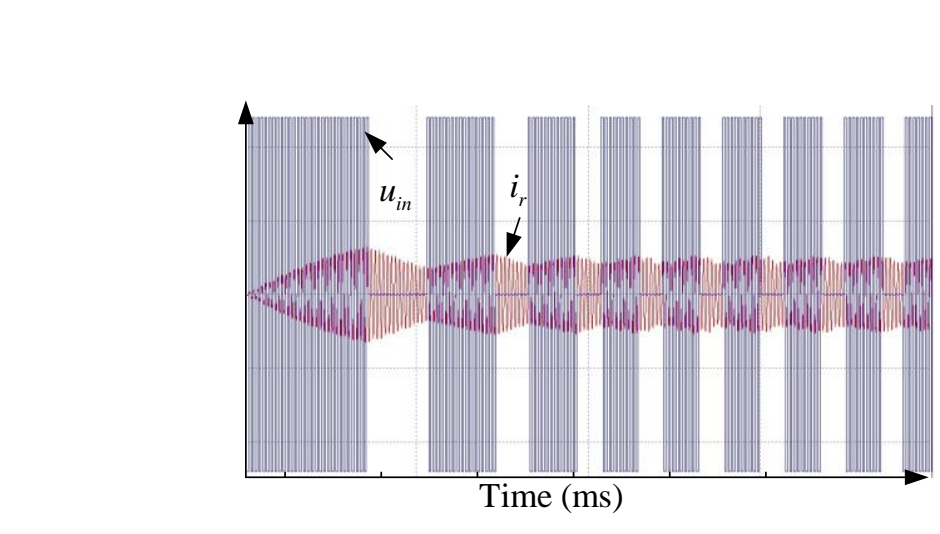

Figure 7. Waveforms of CPT System based on Quantum Modulation

Figure 8shows switching event of CPT system. From the simulation results, it can be knoyn that the resonant current performance a perfect sine waveform. Simultaneously, all the swiches in this circuit operate in zero current switching and zero voltage condition. It is obvious that the inverter based on quantum modulation display high efficiency. Furthermore, Figure 9 shows the step response with the reference voltage 15V. According the plot, the novel controller based on quantum modulation can obtain a stable output voltage in a short settle time. 


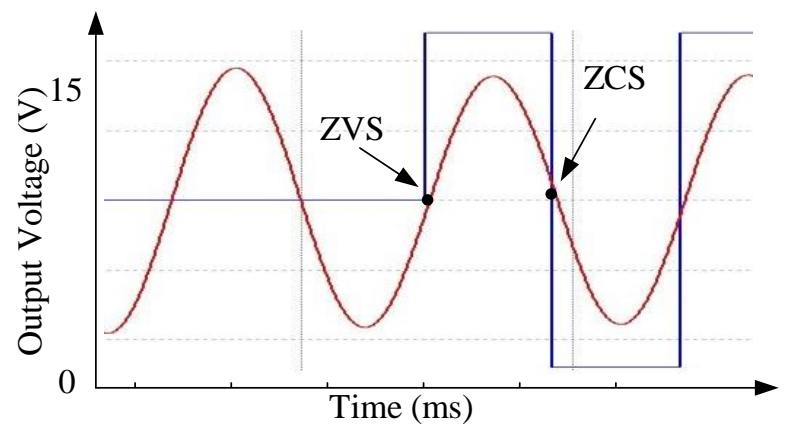

Figure 8. Soft Switching

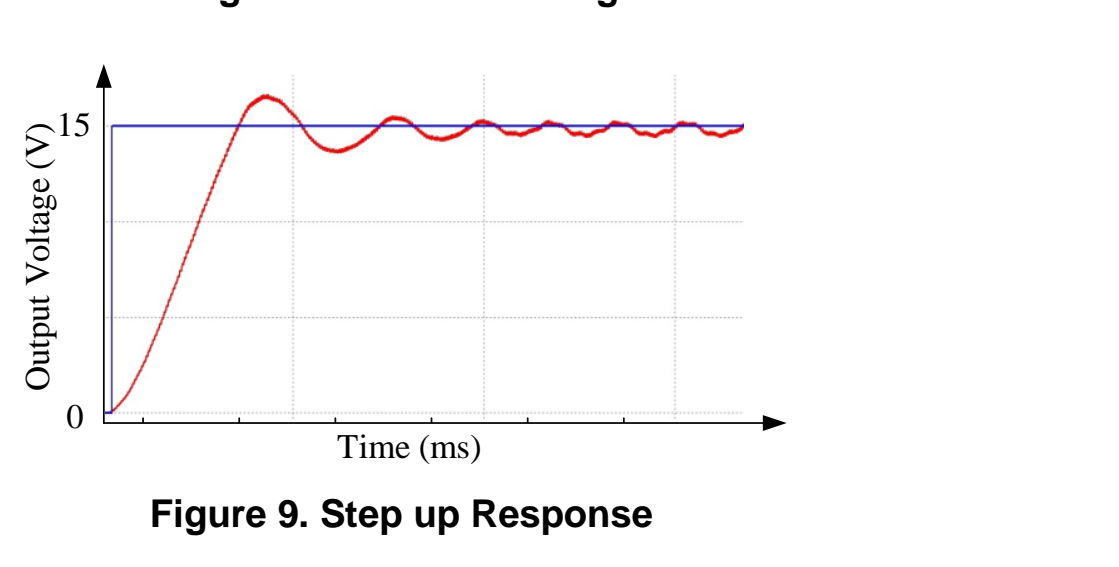

The second and following pages should begin 1.0 inch $(2.54 \mathrm{~cm})$ from the top edge. On all pages, the bottom margin should be $133 / 16$ inches $(2.86 \mathrm{~cm})$ from the bottom edge of the page for $8.5 \times 11$-inch paper; for A4 paper, approximately $1-5 / 8$ inches $(4.13 \mathrm{~cm})$ from the botton edge of the page.

\section{Conclusions}

In this paper, the problem of designing a bidirectional CPT system based on LC-T-LC resonant tank has been add̂resed. The quantum modulation is introduced in this system. First, the mathematical model of LC-T-LC resonant converter in frequency domain is established. The output voltage gain and phase characteristic are deduced as well. The optimal frequency and soft switching region are suggested by the model. Then, a promising control method named quantum modulation is proposed. This method ensures high efficiency of CPT system because it operates with soft switching in the whole load range. Furthermore, the design method of the controller based on a simple analogue circuit is shown in close form. Finally, the simulation results validate the theory proposed in this paper.

\section{Acknowledgements}

This work is supported by Project 51277120 by National Science Foundation of China and ITER Special Project (2011GB113005). This work is also supported by State Energy Smart Grid R\&D Centre (China, Shanghai). 


\section{References}

[1] J. T. Boys, G. A. Covic, and X. Yongxiang, "DC analysis technique for inductive power transfer pick-ups", IEEE Power Electronics Letters, vol. 1, (2003), pp. 51-53.

[2] J. Yungtaek and M. M. Jovanovic, "A contactless electrical energy transmission system for portabletelephone battery chargers", IEEE Transactions on Industrial Electronics, vol. 50, (2003) , pp. 520-527.

[3] C. Tso-Sheng and C. L. Chen, "A primary side control method for wireless energy transmission system", IEEE Transactions on Circuits and Systems, vol. 59, (2012), pp. 1805-1814.

[4] D. Dan and L. Jing, "Design of a practical human-powered contactless charger for cellphone", IEEE Transactions on Consumer Electronics, vol. 59, (2013), pp. 476-482.

[5] S. Raabe and G. A. Covic, "Practical design considerations for contactless power transfer quadrature pickups", IEEE Transactions on Industrial Electronics, vol. 60, (2013), pp. 400-409.

[6] Y. L. Juan and Y. L. He, "Single-stage pickup with a bidirectional zero-voltage turn-on switch", IET Power Electronics, vol. 6, (2013), pp. 693-699.

[7] W. Chwei-Sen, O. H. Stielau, and G. A. Covic, "Design considerations for a contactless electric vehicle battery charger", IEEE Transactions on Industrial Electronics, vol. 52, (2005), pp. 1308-1314.

[8] J. Sallan, J. L. Villa, A. Llombart, and J. F. Sanz, "Optimal design of ICPT systems applied to electric vehicle battery charge", IEEE Transactions on Industrial Electronics, vol. 56, (2009), pp. 2140-2149.

[9] S. Hasanzadeh, S. Vaez-Zadeh, and A. H. Isfahani, "Optimization of a contactless power transfer system for electric vehicles", IEEE Transactions on Vehicular Technology, vol 61, (2012), pp. 3566-3573.

[10] J. Seungmin, L. Hansang, S. Chong Suk, H. Jong-Hoon, H. Woon-Ki, and J. Gilsoo, "Opumal operation plan of the online electric vehicle system through establishment of a DC distribution systen", IEEE Transactions on Power Electronics, vol. 28, (2013), pp. 5878-5889.

[11] G. Elliott, S. Raabe, G. A. Covic, and J. T. Boys, "Multiphase pickups for large lateral tolerance contactless power-transfer systems", IEEE Transactions on Industrial Electronics, vol. 57, (2010) pp. 1590-1598.

[12] J. Huh, S. W. Lee, W. Y. Lee, G. H. Cho, and C. T. Rim, "Narrow-widthinductive power transfer system for online electrical vehicles", IEEE Transactions on PowerElectronics, vol. 26, (2011), pp. 3666-3679.

[13] M. Budhia, J. T. Boys, G. A. Covic, and $\underline{H}$. Chang-Yu "Deyelopment of a single-sided flux magnetic coupler for electric vehicle IPT charging systens", IEEE Transactions on Industrial Electronics, vol. 60, (2013), pp. 318-328.

[14] S. Chopra and P. Bauer, "Driving range extension of EV with on-road contactless power transfer: a case study", IEEE Transactions on Industrial Electronics, vol 60, (2013), pp. 329-338.

[15] U. K. Madawala and D. J. Thrimawithana, "A bidinectional inductive power interface for electric vehicles in V2G systems", IEEE Transactions on Industria Electronics, vol. 58, (2011), pp. 4789-4796.

[16] U. K. Madawala and D. J Thrimawithana, "Current sourced bi-directional inductive power transfer system", IET Power Electronics, Ol. 4, (2011), pp 471-480.

[17] A. K. Swain, M. J. Neath, U. K. Madawala, and D. J. Thrimawithana, "A dynamic multivariable state-space model for bidirectional,inductive power transfer systems", IEEE Transactions on Power Electronics, vol. 27, (2012), pp. $4772-4780$.

[18] D. J. Thrimawithana, U. K. Madawala, and M. Neath, "A synchronization technique for bidirectional IPT systems", IEEE Transactions on Industrial Electronics, vol. 60, (2013), pp. 301-309.

[19] U. K. Madawala, M. Neath, and D. J. Thrimawithana, "A power-frequency controller for bidirectional inductive power transier systems", IEEE Transactions on Industrial Electronics, vol. 60, (2013), pp. 310-317.

[20] M. J. Neath, A. K. Swain, U. K. Madawala, and D. J. Thrimawithana, "An optimal PID controller for a bidirectional inductive power transfer system using multiobjective genetic algorithm", IEEE Transactions on Power Electronics, vol. 29, (2014), pp. 1523-1531.

[21] F. F. A. Van der Pijl, P. Bauer, J. A. Ferreira, and H. Polinder, "Quantum control for an experimental contactess energy transfer system for multiple users", in Power Electronics Specialists Conference, PESC 2007. IEEE, pp. 343-349, (2007) June; Orlando, USA

[22] H.Li, A. P. Hu, and G. A. Covic, "Current fluctuation analysis of a quantum ac-ac resonant converter for contactless power transfer", in Energy Conversion Congress and Exposition (ECCE), IEEE, 2010, pp. 18381843, (2010) September; Atlanta, USA

[23] F. Van der Pijl, M. Castilla, and P. Bauer, "Implementation of an adaptive sliding-mode control for a quantum series-resonant converter", in Power Electronics and Applications. EPE '09. 13th European Conference on, pp. 1-10, (2009) September; Barcelona, Spain

[24] L. G. de Vicuna, M. Castilla, J. Miret, J. Matas, and J. M. Guerrero, "Sliding-mode control for a single-phase AC/AC quantum resonant converter", IEEE Transactions on Industrial Electronics, vol. 56, (2009), pp. 34963504. 
[25] H. Y. Leung, D. McCormick, D. M. Budgett, and A. P. Hu, "Pulse density modulated control patterns for inductively powered implantable devices based on energy injection control", IET Power Electronics, vol. 6, (2013) , pp. 1051-1057.

[26] F. F. A. van der Pijl, M. Castilla, and P. Bauer, "Adaptive sliding-mode control for a multiple-user inductive power transfer system without need for communication", IEEE Transactions on Industrial Electronics, vol. 60, (2013), pp. 271-279.

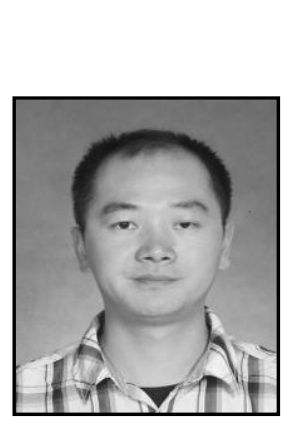

\section{Authors}

Jianyu Lan, he received his B.S. in Industrial Automation (2002) from Zheng Zhou University and M.S. in Power Electronic (2009) from Shanghai Maritime University. Currently he is working toward his Ph. D. degree in electrical engineering at Shanghai Jiao Tong University. His research interests include power electronics, resonant converter and wireless power transfer system.

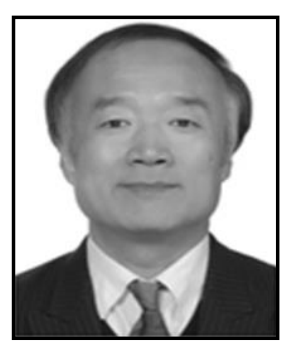

Houjun Tang, he received B.S. in 1957 and M.S. in1982, respectively. $\mathrm{He}$ received his $\mathrm{Ph}$. D. degree in Electrical Engineering at Yamagata University. He is currently a professor of the Department of Electrical Engineering in Shanghi Jiao Tong University. His current research interests include power electronics and wireless power transfer system.

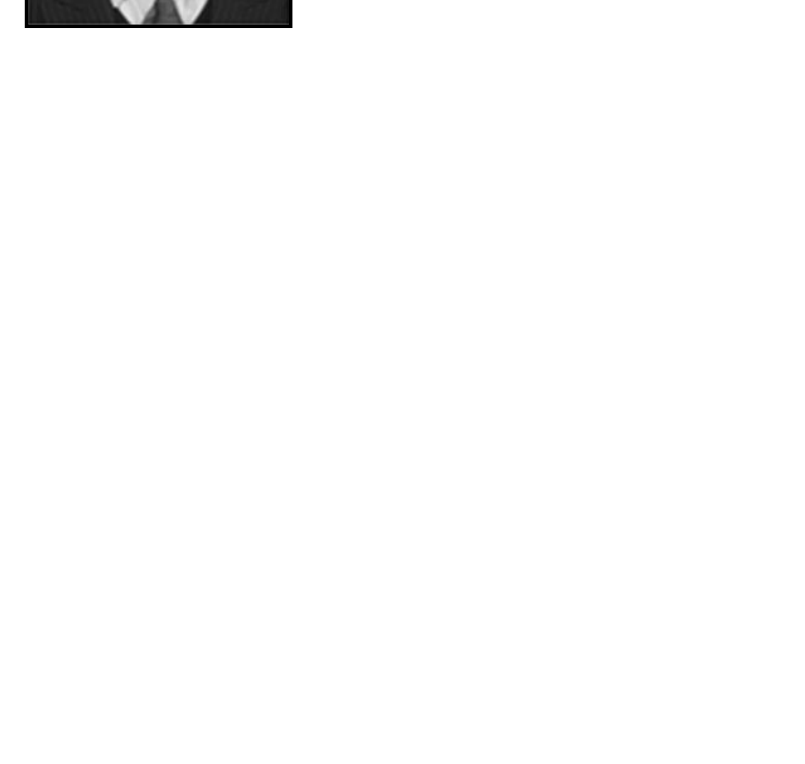

